\title{
DESENVOLVIMENTO DE DISPOSITIVO PARA SOLDAGEM COM ELETRODOS REVESTIDOS POR GRAVIDADE E APLICAÇÃO EM ESTUDO DE METALURGIA DA SOLDAGEM DE AÇO API X65Q *
}

Thaís Ávila Braz ${ }^{1}$ Tairine Berbert Tavares ${ }^{1}$ Rodrigo Rangel Porcaro ${ }^{2}$

Luiz Cláudio Cândido ${ }^{3}$ Geraldo Lúcio de Faria ${ }^{4}$

\section{Resumo}

Desenvolveu-se um dispositivo para soldagem por gravidade com eletrodos revestidos e investigou-se o comportamento do dispositivo em função de variações nas condições operacionais. Ciclos térmicos durante a deposição de cordões em tubos de aço API X65Q foram avaliados por meio de medidas experimentais, utilizando-se termopares inseridos na poça de fusão durante a soldagem por gravidade. Amostras do metal base e do cordão depositado em diferentes condições de aporte térmico passaram por análise química, microestrutural e metalográfica. Observou-se boa repetibilidade na velocidade de deposição do dispositivo e aspecto visual adequado de cordões de solda depositados. Os resultados dos ciclos térmicos mostram que as variações nos valores de $\Delta$ t800/500, utilizando eletrodos AWS E7018 e correntes de soldagem de $70 \mathrm{~A}$ e $150 \mathrm{~A}$, causaram redução de $21 \%$ na proporção de ferrita acicular e, consequente, redução de $22 \%$ nos valores de microdureza do metal de solda com maior aporte térmico.

Palavras-chave: SMAW; Soldagem por Gravidade; Metalurgia da Soldagem.

\section{DEVELOPMENT OF A DEVICE FOR GRAVITY WELDING WITH COVERED ELECTRODES AND APPLICATION IN A WELDING METALLURGY STUDY IN AN API X65Q STEEL}

\section{Abstract}

This study has been carried out to develop an equipment to perform a variation of Shielded Metal Arc Welding, known as gravity welding and the effects of changes in the welding parameters were evaluated. Furthermore, based on this equipment, thermal cycles were obtained by inserting thermocouples in the welding fusion line, during deposition of welding beads in an API X65Q pipeline steel. Samples of the asreceived material and weld metal were taken for chemical analysis and further microstructural characterization and hardness measurements. It was found that the visual aspect of the weld beads are satisfactory, and the welding speed of the equipment presents good repeatability. The results of the thermal cycles investigation with AWS E7018 electrode, indicated that the change in the welding current from $70 \mathrm{~A}$ to $150 \mathrm{~A}$, leads to a $21 \%$ reduction in acicular ferrite content, reducing hardness values of the weld metal in $22 \%$.

Keywords: SMAW; Gravity Welding; Welding Metallurgy.

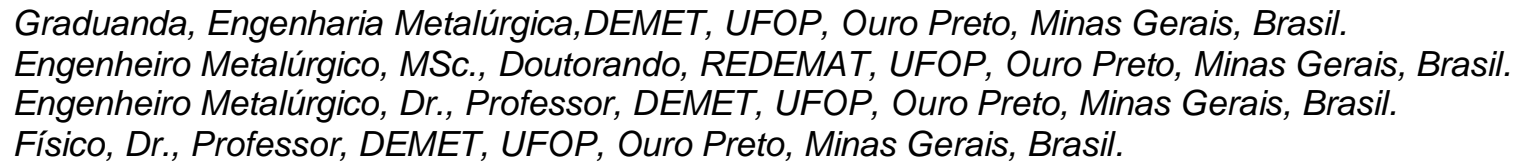




\section{INTRODUÇÃO}

O processo de soldagem por eletrodos revestidos é uma técnica de soldagem manual que pode utilizar diversos tipos de eletrodos no que diz respeito ao revestimento (rutílico, básico, celulósico, etc.). É muito empregado na soldagem de tubos de pequenos e médios diâmetros e em uniões de baixa e alta responsabilidade, por apresentar simplicidade e qualidade satisfatória do cordão depositado. Por apresentar muitas possibilidades de combinação alma-revestimento, a soldagem por eletrodos revestidos é vantajosa no quesito controle da composição química do cordão de solda e, consequentemente, maior controle microestrutural [1]. A integridade de uma junta soldada é diretamente ligada à simetria do cordão de solda depositado e à homogeneidade dos constituintes presentes, além da ausência de descontinuidades. Por ser um processo manual, a soldagem com eletrodos revestidos exige maior treinamento e habilidade do soldador, uma vez que esse influencia na qualidade e repetibilidade do cordão de solda, dificilmente repetindo os mesmos movimentos durante a deposição no processo [2].

Com o objetivo de automatizar o processo, surgiram algumas variações, as quais minimizam a influência do operador e garantem maior repetibilidade. Uma variação mecanizada do processo é conhecida como soldagem com eletrodos revestidos por arraste ou por gravidade [3].

Davis e Ferjutz [4] conceituam a soldagem por gravidade como um mecanismo de baixo custo que aumenta a produtividade, já que é possível operar mais de um dispositivo ao mesmo tempo, além de não requisitar altos níveis de treinamento por parte dos soldadores, diminuindo custos com mão de obra especializada. $O$ dispositivo, em geral, é composto por um eletrodo preso a um mecanismo móvel, que desliza sobre uma barra guia inclinada [1].

Apesar de ser um processo muito simples, a soldagem por gravidade possui algumas limitações normalmente geradas pela montagem do mecanismo, que permite soldagem apenas na posição plana [5]. Um grande interesse desse tipo de processo é a sua aplicação em estudos de metalurgia da soldagem, uma vez que os principais parâmetros que controlam o aporte de calor (corrente, velocidade de soldagem e comprimento de arco) são praticamente constantes durante a operação.

A caracterização microestrutural e avaliação de propriedades mecânicas de juntas soldadas de aços API X65 se torna importante a partir do momento em que o aço é muito usado na confecção de dutos para transporte de gás e petróleo por meio da soldagem de tubos [6].

Nesse trabalho, foi desenvolvido um dispositivo de soldagem por gravidade que manteve fixas algumas condições de soldagem, por exemplo, a velocidade de deposição, o que permitiu a aplicação do processo em estudos de Metalurgia da Soldagem com maior repetibilidade e a possibilidade de controle de aporte de calor. Em uma dessas aplicações, cordões de solda foram depositados sobre segmentos de tubo sem costura de aço API X65Q em duas condições de aporte térmico e, posteriormente, avaliou-se a microestrutura e propriedades mecânicas dos cordões produzidos.

Os resultados obtidos mostram que é viável o emprego de mecanização do processo de soldagem por eletrodos revestidos com o objetivo de minimizar a influência do operador em estudos de Metalurgia da Soldagem. 


\section{MATERIAIS E MÉTODOS}

\subsection{Desenvolvimento e Avaliação do Dispositivo para Soldagem por Gravidade}

De acordo com Felizardo [1], a qualidade do cordão de solda, assim como a não possibilidade de controle da velocidade de mergulho do eletrodo, são fatores que comprometem a eficiência do processo de soldagem por gravidade. Por essa razão, o presente trabalho desenvolveu o projeto de dispositivo apresentado na Figura 1. 0 projeto compreendeu em um porta eletrodo (a), que se desloca em uma guia (b) à medida que o eletrodo (c) é consumido. O controle da velocidade de avanço do eletrodo é realizado por meio de contra-pesos adicionados à barra (d). Uma cordoalha de algodão controla a velocidade de descida do carro (a) e passa pelas roldanas representadas na barra (b) e na haste em (d).

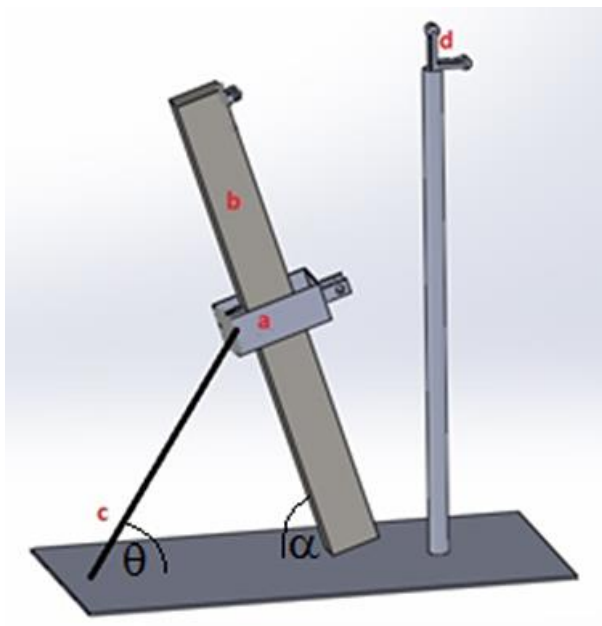

Figura 1. Projeto do dispositivo de soldagem por gravidade. (a) porta eletrodos, (b) guia, (c) eletrodo revestido, (d) haste na qual um contrapeso controla a velocidade de descida do eletrodo. $(\theta)$ ângulo de ataque do eletrodo, ( $\alpha$ ) ângulo de inclinação da haste guia.

A repetibilidade do dispositivo de soldagem por gravidade na deposição de cordões e a seleção dos ângulos de trabalho indicados na Figura 1 foram avaliados a partir de ensaios exploratórios com eletrodos AWS E6013 (2,5mm de diâmetro) e chapas base de aço ASTM A36 (8,1mm de espessura). Para isso, observou-se 0 comportamento do dispositivo em relação à movimentação do porta eletrodo, a largura dos cordões depositados e o aspecto geral da solda.

Umas das variáveis mais importantes na soldagem é a velocidade média de deslocamento da fonte de calor. A relação entre velocidade de soldagem e corrente determina o aporte térmico, dado pela Equação 1 [7].

$$
\mathrm{Q}=\eta \mathrm{VI} / \mathrm{V}
$$

Onde $\eta$ é a eficiência térmica ou rendimento do processo, $V$ é a tensão em volts, I é a corrente em ampères e $v$ a velocidade de soldagem em $\mathrm{mm} / \mathrm{s}$.

A influência do tipo de eletrodo, diâmetro e corrente de soldagem na velocidade média de deposição foi avaliada a partir de testes em triplicata com as seguintes condições: eletrodos AWS E6013 com diâmetro de 2,5mm operando em $70 \mathrm{~A}$ e 100A; eletrodos AWS E7018 com diâmetro de 2,5mm operando com $70 \mathrm{~A}$ e diâmetro de $3,35 \mathrm{~mm}$ operando com $120 \mathrm{~A}$ e $150 \mathrm{~A}$. 
Em uma segunda etapa, a influência da massa do eletrodo na velocidade média de deposição foi avaliada, pois, uma vez que a deposição depende do peso do sistema para deslocamento do porta eletrodo e tem-se o consumo do eletrodo, a massa do conjunto formado pelo porta eletrodo varia à medida que o cordão é depositado. As medidas foram realizadas em triplicata, com eletrodos AWS E6013 (2,5mm) e E7018 $(3,25 \mathrm{~mm})$ com correntes de $100 \mathrm{~A}$ e $150 \mathrm{~A}$, respectivamente. Em princípio, criou-se uma marca visual na metade do eletrodo e, após abertura e estabilização do arco elétrico, iniciou-se a cronometragem até o consumo de sua primeira metade. 0 mesmo foi realizado para a segunda metade, podendo-se assim calcular as velocidades médias de deposição para as partes.

\subsection{Aplicação do Dispositivo em Estudos de Metalurgia da Soldagem}

Após determinada a velocidade média de deposição do dispositivo, assim como a influência do tipo/diâmetro do eletrodo e da corrente de soldagem sobre a velocidade média, cordões de solda foram depositados em segmentos de aço API X65Q obtidos de tubo sem costura com 9 5/8" de diâmetro e 12,17mm de espessura de parede. Utilizaram-se eletrodos do tipo AWS E7018, geralmente aplicados em soldagem de alta responsabilidade. Os cordões foram depositados com dois níveis de aporte térmico; (i) $70 \mathrm{~A}$ (eletrodos de $2,5 \mathrm{~mm}$ de diâmetro) e (ii) 150A (eletrodos de $3,25 \mathrm{~mm}$ de diâmetro). Em todas as condições foi utilizada fonte de corrente contínua com eletrodo positivo $\left(\mathrm{CC}^{+}\right)$.

Amostras dos cordões de solda para caracterização metalográfica foram cuidadosamente retiradas para obter regiões nas quais os cordões depositados fossem o mais homogêneo possível (região central), e então preparadas segundo os procedimentos usuais para metalografia, com ataque químico com o reagente Nital $2 \%$ no Laboratório de Tratamentos Térmicos e Metalografia do DEMET/UFOP.

Após o ataque, as amostras foram analisadas em microscópio óptico Leica e fotografadas com aumentos de 50X, 100X, 200X, 500X e 1000X. Aplicou-se ainda metalografia quantitativa no metal de solda a partir do método dos interceptos com contagem manual dos constituintes, segundo o modelo proposto pelo Instituto Internacional de Soldagem IIW [8]. Para a quantificação dos constituintes no metal de solda foram utilizadas imagens com aumento de 500X e uma malha com 100 pontos, em 20 campos diferentes para cada condição de soldagem, conforme Norma ASTM E562 (2011) [9]. Os valores das médias dos constituintes nas duas condições foram avaliados aos pares por testes t de Student com 95\% de confiança para verificar a significância estatística dos resultados.

Traçaram-se perfis de microdureza Vickers nas diversas regiões de cordões depositados no aço API X65Q nas condições de maior e menor aporte térmico (70A e 150A), a fim de complementar a caracterização da microestrutura ao longo da junta. Os ensaios de microdureza foram realizados segundo a Norma ASTM A370 (2012) [10], com carga de 100gf por 15s. As indentações foram feitas com espaçamento de $0,2 \mathrm{~mm}$, abrangendo o metal base, toda a ZTA e a zona fundida.

Os ciclos térmicos desenvolvidos no metal de solda foram medidos por meio da inserção de termopares do tipo Platina/Ródio-Platina, com diâmetro de 0,40mm, em poças de fusão durante a deposição por gravidade. Os dados de temperatura em função do tempo foram obtidos por um coletor de sinais para as duas condições de aporte térmico do estudo. 


\section{RESULTADOS E DISCUSSÃO}

\subsection{Desenvolvimento do Dispositivo e Variáveis Operacionais}

Inicialmente, foi desenvolvido um protótipo (Figura 2 (a)), que apresentou problemas durante a soldagem, como: flexão do eletrodo após abertura do arco elétrico, velocidade de mergulho do eletrodo instável, gerando cordões de solda de má qualidade, como também relatado por Felizardo [1] em seu trabalho. Os problemas foram identificados e atribuídos ao mau acabamento da haste guia e ao excesso de peso do conjunto porta eletrodo/cabo. Desenvolveu-se então um segundo dispositivo (Figura 2 (b)), contando com materiais de maior qualidade e menor peso na barra guia do porta eletrodo, além de se utilizar um cabo condutor de maior flexibilidade e ancorado em uma posição fixa.

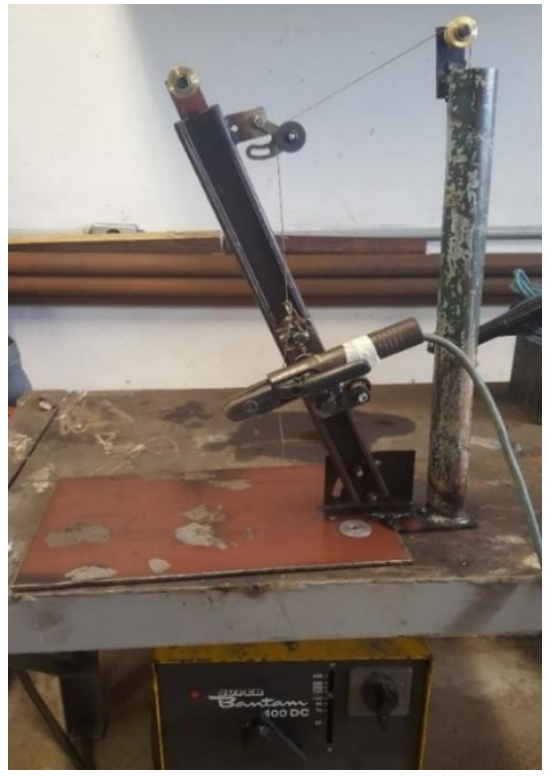

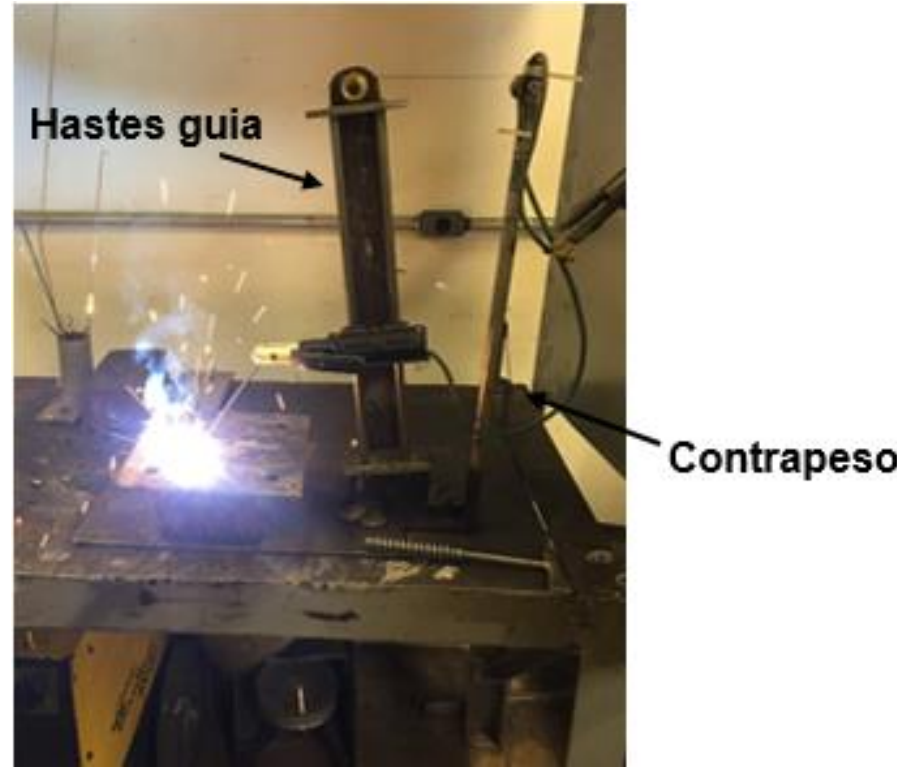

(b)

Figura 2. Dispositivos de soldagem por gravidade desenvolvidos no projeto. (a) protótipo inicial e (b) versão final com barra guia polida e contrapeso ajustável.

A barra guia da segunda versão foi confeccionada a partir de hastes de aço polidas e com rolamentos de precisão desenvolvidos para impressoras 3D, o que reduziu o atrito e permitiu maior repetibilidade na soldagem. Contrapesos variáveis de chumbo foram adicionados para o controle da velocidade de mergulho do eletrodo e se mostraram eficientes para reduzir a tendência de flexão no início da soldagem com eletrodos de 2,5mm e diminuir a ocorrência de curtos-circuitos.

Os ângulos $\theta$ e $\alpha$ apresentados na Figura 1 foram definidos como $60^{\circ}$ e $85^{\circ}$, respectivamente. Os valores foram aqueles que apresentaram os melhores resultados na deposição dos cordões, sendo mantidos em todos os experimentos.

$\mathrm{Na}$ Tabela 1 são apresentadas as velocidades médias de deposição, largura e altura de cordões depositados pelo dispositivo nas diferentes condições avaliadas. Podese observar que a velocidade de deposição dos cordões apresenta boa repetibilidade e que o aumento da corrente resulta em aumento na velocidade de deposição, fato que se relaciona com o maior consumo de eletrodo. De acordo com Farias e Dutra [11], a largura do cordão de solda aumenta com o aumento do diâmetro do eletrodo, bem como observado para o eletrodo AWS E7018. 
Tabela 1. Velocidade média de deposição, largura e altura de cordões de solda em diferentes condições operacionais

\begin{tabular}{c|c|c|c|c|c}
\hline Tipo Eletrodo & Corrente (A) & $\begin{array}{c}\text { Velocidade } \\
\mathbf{( m m} / \mathbf{s})\end{array}$ & $\begin{array}{c}\text { Desvio } \\
\text { Padrão }\end{array}$ & Largura (mm) & Altura (mm) \\
\hline E7018 (2,5mm) & 70 & 2,50 & 0,22 & 6,00 & 2,67 \\
\hline E7018 (3,25mm) & 120 & 2,70 & 0,21 & 7,33 & 3,33 \\
\hline E7018 (3,25mm) & 150 & 2,90 & 0,06 & 8,03 & 2,93 \\
\hline E6013 (2,5mm) & 70 & 2,70 & 0,38 & 4,33 & 2,00 \\
\hline E6013 (2,5mm) & 100 & 3,20 & 0,20 & 6,67 & 1,50 \\
\hline
\end{tabular}

Nota-se a partir da Figura 3 que a qualidade do cordão depositado com eletrodo AWS E7018 é, no geral, melhor que o eletrodo AWS E6013, apresentando menos respingos e desvios laterais. Essas observações também são relatadas por Cavalcanti [12], que encontrou melhor aspecto visual em cordões depositados por gravidade com eletrodos básicos AWS E7018 quando comparados aos rutílicos AWS E6013. Além disso, nos eletrodos básicos com menor aporte de calor foram observados maiores desvios laterais e maior desvio padrão na velocidade de deposição, parâmetros que se tornam mais estáveis à medida que se aumenta a corrente. Pode-se atribuir esses resultados ao diâmetro dos eletrodos, uma vez que maior diâmetro implica em maior rigidez, o que reduz a tendência à flexão durante a deposição dos cordões.

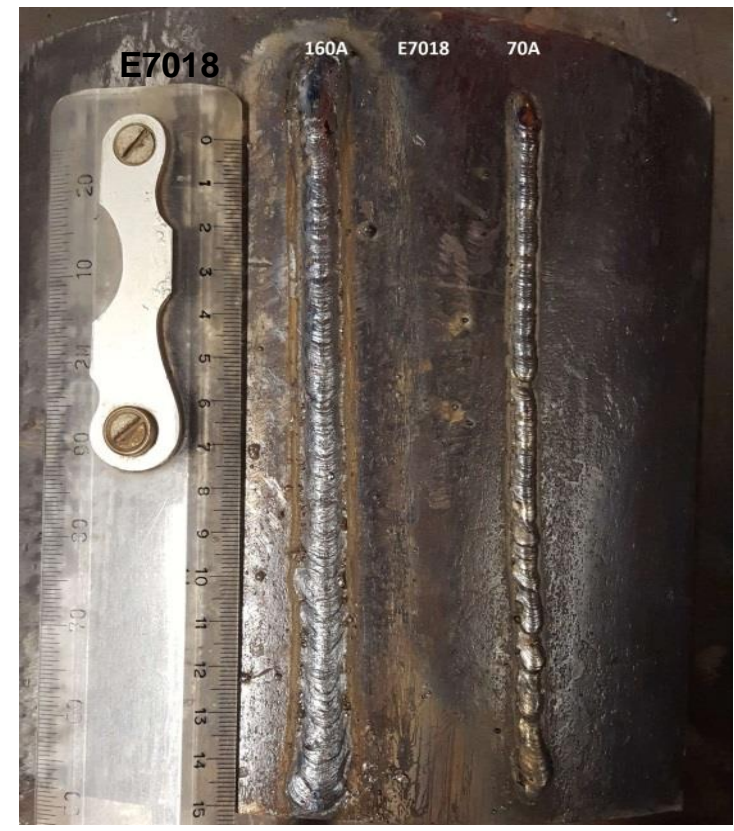

(a)

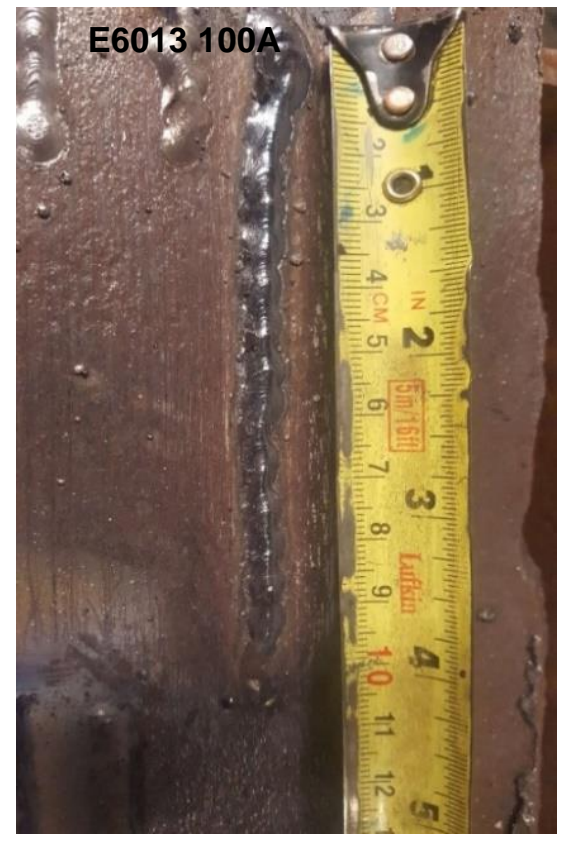

(b)

Figura 3. (a) Cordões depositados pelo dispositivo com eletrodos básicos AWS E7018 e correntes de $70 \mathrm{~A}(2,5 \mathrm{~mm})$ e 150A (3,25mm); (b) Cordão depositado pelo dispositivo, eletrodo AWS E6013 (2,5mm) e corrente de $100 \mathrm{~A}$.

$\mathrm{Na}$ Tabela 2 são apresentados os resultados de velocidade de deposição média para a primeira e a segunda metade dos eletrodos. Nota-se que para os eletrodos E6013 de 2,5mm de diâmetro, a velocidade média de deposição praticamente não variou em função de seu consumo. No entanto, para os eletrodos AWS E7018 de $3,25 \mathrm{~mm}$ de diâmetro, a velocidade média de deposição foi significativamente menor entre a primeira e a segunda metade do eletrodo. Tal resultado pode ser atribuído à massa dos eletrodos, uma vez que o eletrodo AWS E7018 possui maior peso, alma com $3,25 \mathrm{~mm}$ e pó de ferro no revestimento, ou seja, à medida que o eletrodo é 
consumido, o peso do conjunto descendente do dispositivo por gravidade é reduzido de forma mais significativa que para o eletrodo AWS E6013.

Tabela 2. Velocidade média de deposição para a primeira e segunda metade dos eletrodos

\begin{tabular}{c|c|c|c|c|c}
\hline $\begin{array}{c}\text { Tipo Eletrodo } \\
\text { (AWS) }\end{array}$ & Corrente (A) & $\begin{array}{c}\text { Velocidade } \\
\text { Primeira } \\
\text { Metade } \\
\text { (mm/s) }\end{array}$ & $\begin{array}{c}\text { Desvio } \\
\text { Padrão }\end{array}$ & $\begin{array}{c}\text { Velocidade } \\
\text { Segunda } \\
\text { Metade (mm/s) }\end{array}$ & Desvio Padrão \\
\hline E6013(2,5mm) & 100 & 3,51 & 0,03 & 3,53 & 0,09 \\
\hline E7018(3,25mm) & 150 & 3,53 & 0,04 & 2,62 & 0,18 \\
\hline
\end{tabular}

Pela observação dos cordões na Figura 4 é possível concluir que os cordões depositados com a segunda metade dos eletrodos possuem maior qualidade, com menos mordeduras visíveis, menor deflexão lateral e maior constância da largura. Tais características podem ser conferidas à menor tendência à flexão em eletrodos de menor comprimento.

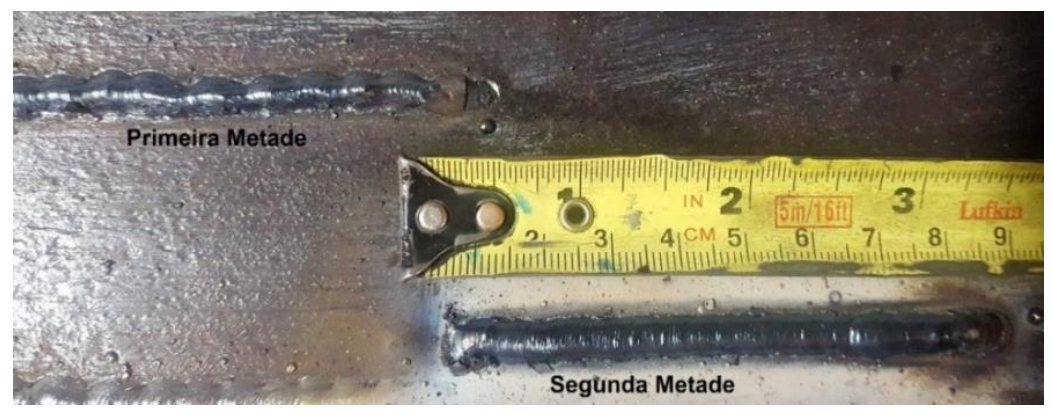

(a) AWS E6013

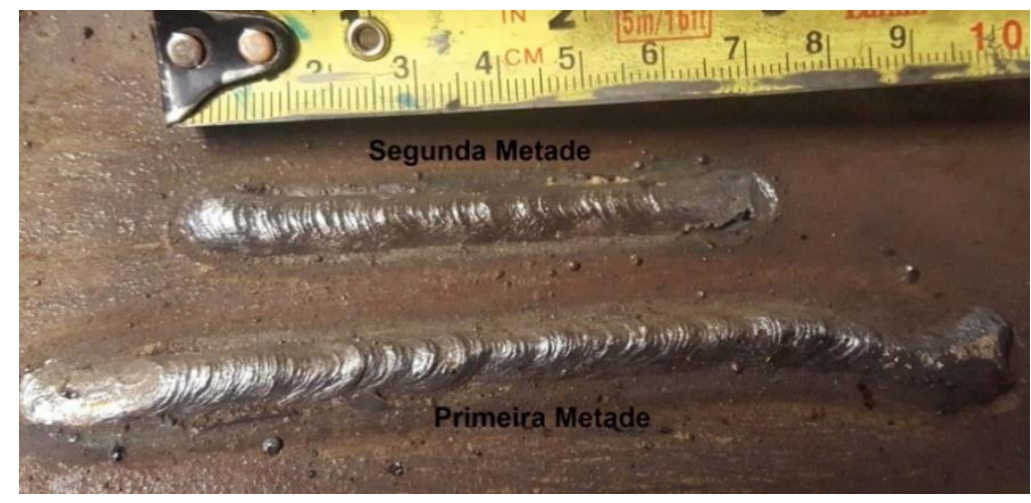

(b) AWS E7018

Figura 4. Primeira e segunda metade de cordões depositados com (a) eletrodos AWS E6013 $(2,5 \mathrm{~mm})$ e corrente de $100 \mathrm{~A}$ e, (b) eletrodos AWS E7018 $(3,25 \mathrm{~mm})$ e corrente de 150A.

\subsection{Aplicação em Estudos de Metalurgia da Soldagem}

Pela Tabela 3 é possível observar que a composição química do metal base do tubo de aço API X65Q se enquadra nos padrões especificados pela Norma DNV OS, F101 [13], com carbono equivalente (IIW) igual a 0,35\%. Os valores de todos os elementos não são apresentados devido a pedido de sigilo do fornecedor do aço.

Tabela 3. Composição química dos materiais (\% em massa)

\begin{tabular}{c|c|c|c|c|c|c}
\hline Grau do aço & $\mathrm{C}_{\text {e-IIw }}$ & $\mathrm{P}$ & $\mathrm{S}$ & $\mathrm{Cr}$ & $\mathrm{Mo}$ & $\mathrm{Ni}$ \\
\hline $\mathbf{X 6 5 Q}$ & 0,35 & 0,015 & 0,0015 & 0,046 & 0,071 & 0,158 \\
\hline
\end{tabular}


A Figura 5 ilustra micrografias da seção longitudinal e transversal do metal base, não sendo observadas diferenças significativas entre os constituintes presentes nas mesmas. A microestrutura analisada é composta por martensita revenida.

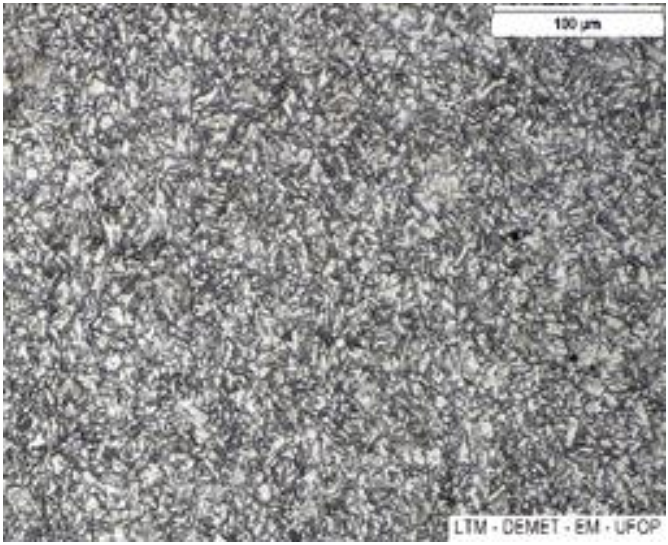

(a)

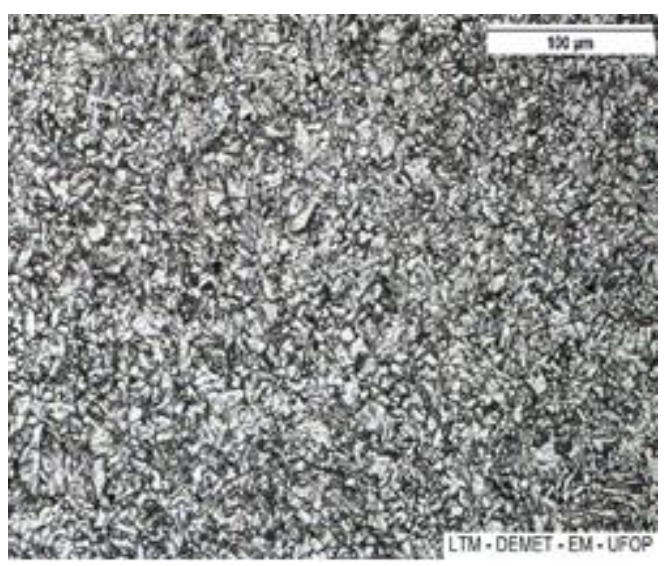

(b)

Figura 5. Micrografias do metal base (Aço API X65Q) (a) Seção longitudinal; (b) Seção Transversal. Ataque Nital 2\%, 200X.

As velocidades de deposição médias para eletrodos AWS E7018 sobre o aço API X65Q foram de $2,50 \mathrm{~mm} / \mathrm{s}$ para corrente igual a $70 \mathrm{~A}$ e $2,90 \mathrm{~mm} / \mathrm{s}$ para corrente igual a $150 \mathrm{~A}$.

Os resultados dos ciclos térmicos obtidos por termopares para as duas condições de aporte térmico avaliadas são apresentados na Figura 6. Pode-se observar que o aumento do aporte de calor com o aumento da corrente soldagem reduziu a taxa de resfriamento do metal de solda. O tempo de permanência entre $800^{\circ} \mathrm{C}$ e $500^{\circ} \mathrm{C}$ $\left(\Delta \mathrm{t}_{800-500}\right)$ foi igual a $4,1 \mathrm{~s}$ e $6,5 \mathrm{~s}$ para corrente de $70 \mathrm{~A}$ e $150 \mathrm{~A}$, respectivamente.

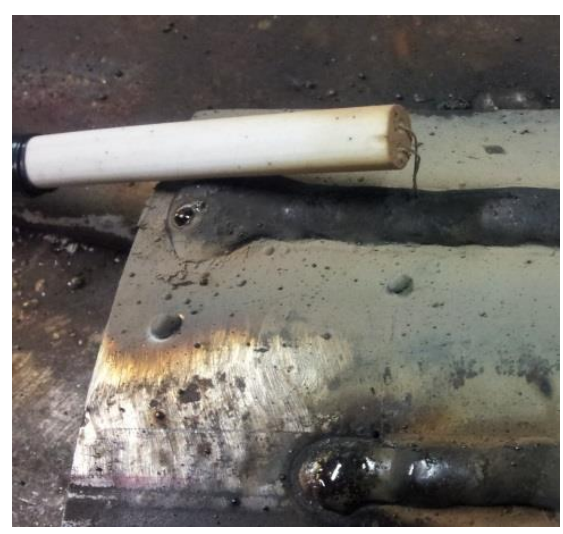

(a)

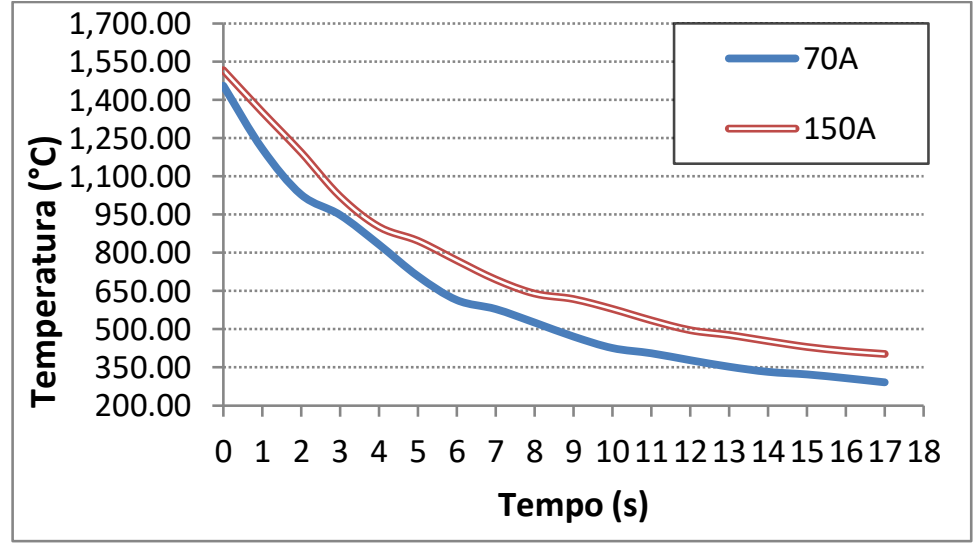

(b)

Figura 6. Ciclos térmicos obtidos por termopares do tipo $S$ inseridos na poça de fusão durante a deposição de cordões com eletrodos AWS E7018 sobre um aço API X65Q. (a) Termopar inserido no cordão de solda; (b) Curvas de resfriamento obtidas para duas condições de soldagem.

A microestrutura típica do metal de solda obtido a partir da deposição de cordões com eletrodos AWS E7018 sobre o aço API X65Q é apresentada na Figura 7. É possível notar que de modo qualitativo ao se comparar as Figuras 7 (a) e (b) que o aporte de calor teve grande influência na formação da microestrutura do metal de solda.

Os resultados de metalografia quantitativa são apresentados na Tabela 4 e mostram de forma quantitativa a influência do aporte de calor na formação dos constituintes 
na ZF; o aumento da corrente de soldagem de $70 \mathrm{~A}$ para $150 \mathrm{~A}$ significou aumento do aporte térmico (Equação 1) de $0,67 \mathrm{~kJ} / \mathrm{mm}$ para $1,24 \mathrm{~kJ} / \mathrm{mm}$. O constituinte que foi mais afetado pelo aumento do aporte de calor foi a ferrita acicular, que sofreu redução de aproximadamente $21 \%$ entre as condições avaliadas, com aumento da proporção de ferritas primárias (FP e $\mathrm{FP}(\mathrm{G})$ ) e de ferrita com segunda fase (FS) no resfriamento mais lento (150A). Testes t de Student realizados nos dados aos pares indicaram, com 95\% de confiança, que tratam-se de médias diferentes, $p<0,05$ para os valores de $F A, F P(G)$ e FS. No entanto, as médias de FP não podem ser consideradas diferentes segundo o teste t de Student, $p>0,05$.

Tabela 4. Metalografia quantitativa do metal de solda depositado sobre o aço API X65Q com eletrodos AWS E7018 em duas condições de aporte de calor

\begin{tabular}{c|c|c|c|c}
\hline & \multicolumn{4}{|c}{ Média de constituintes (\%) } \\
\hline Corrente & FA & FP & FP(G) & FS \\
\hline $\mathbf{7 0 A}$ & $\mathbf{5 3 , 2}$ & $\mathbf{2 6 , 4}$ & $\mathbf{1 5 , 7}$ & $\mathbf{4 , 7}$ \\
\hline Desvio Padrão & 6,4 & 6,5 & 4,4 & 3,1 \\
\hline 150A & $\mathbf{3 1 , 7}$ & $\mathbf{3 0 , 8}$ & $\mathbf{2 5 , 0}$ & $\mathbf{1 2 , 4}$ \\
\hline Desvio Padrão & 10,0 & 10,1 & 7,0 & 7,6 \\
\hline
\end{tabular}

Há uma competição cinética entre os produtos de transformação da austenita nucleados nos contornos e interior dos grãos; diversos fatores influenciam a quantidade e a morfologia da ferrita acicular, citando como principais: a composição do metal de solda, a taxa de resfriamento entre $800^{\circ} \mathrm{C}$ e $500^{\circ} \mathrm{C}\left(\Delta\right.$ t $\left._{800-500}\right)$, teor de oxigênio do metal de solda e o tamanho de grão austenítico [7,14]. A ferrita acicular é uma microestrutura geralmente benéfica para a tenacidade do metal de solda e a sua maior proporção obtida na condição de menor aporte térmico é justificada pelo menor $\Delta$ t800-500 apresentado anteriormente.

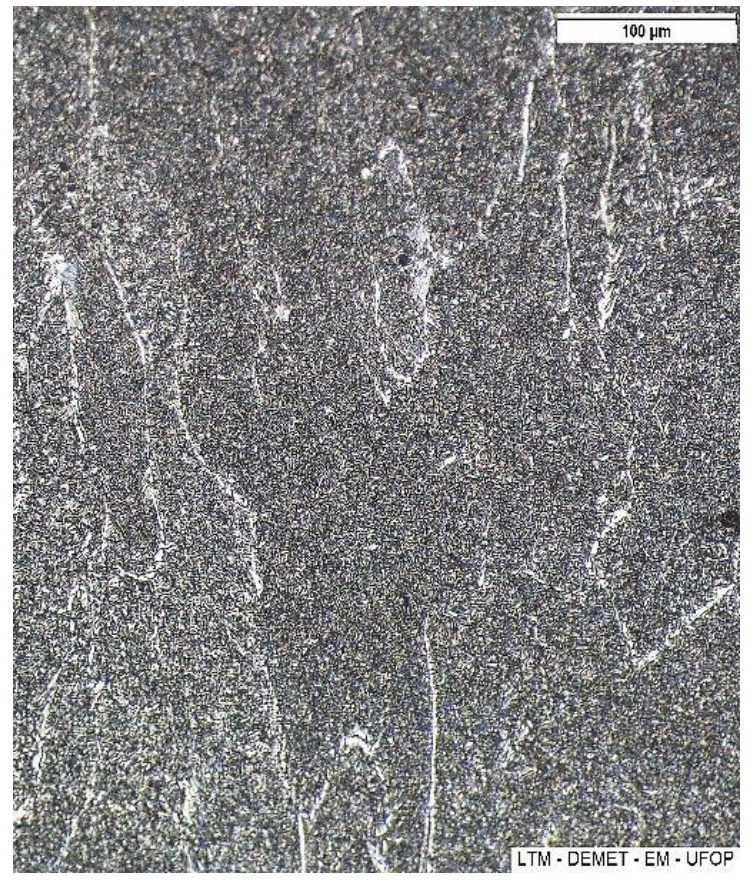

(a)

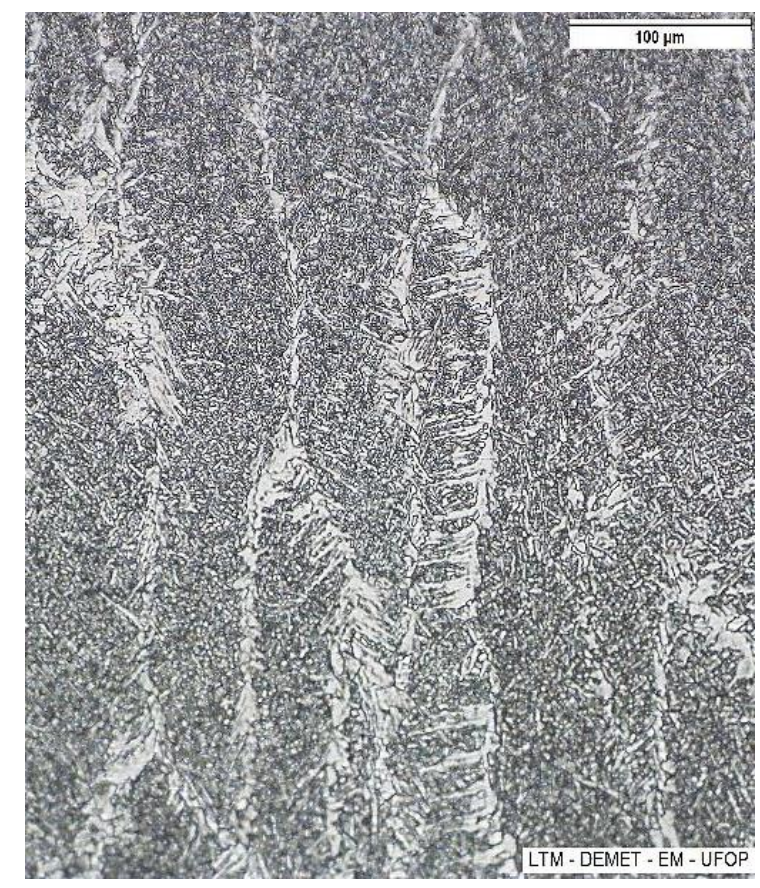

(b)

Figura 7. Micrografias da ZF de cordões depositados sobre o aço API X65Q com eletrodos AWS E7018, em (a) Corrente de 70A; (b) Corrente de 150A. Ataque Nital 2\%, 200x. 
Os resultados dos ensaios de microdureza nos cordões depositados sobre o aço API X65Q estão representados nas Figuras 8 e 9, nas condições de maior e menor aporte térmico, respectivamente.

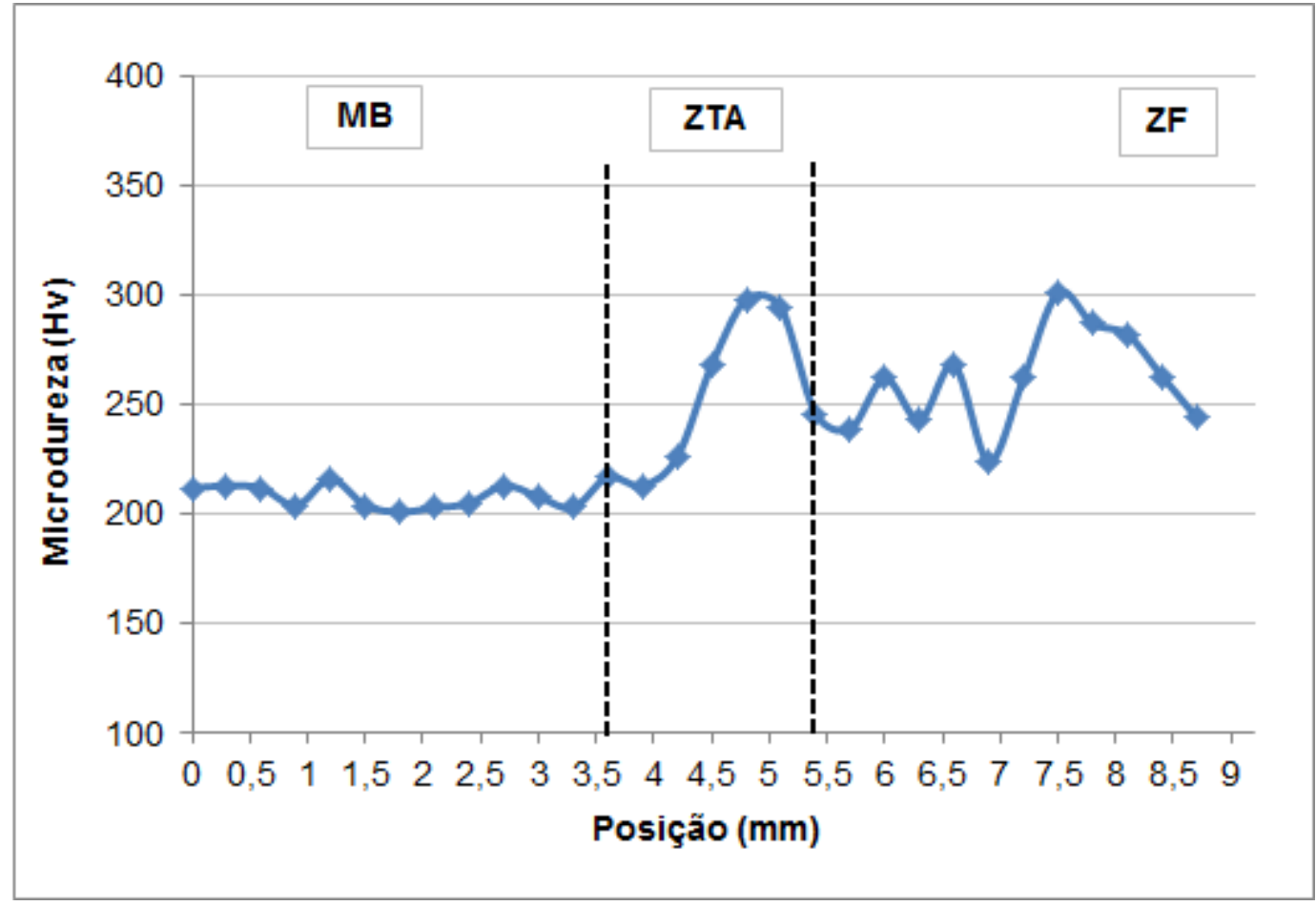

Figura 8. Perfil de microdureza em cordões de solda depositados por eletrodos AWS E7018 sobre aço API X65Q, corrente 150A. MB-Metal base; ZTA-Zona Termicamente Afetada; ZF-Zona Fundida.

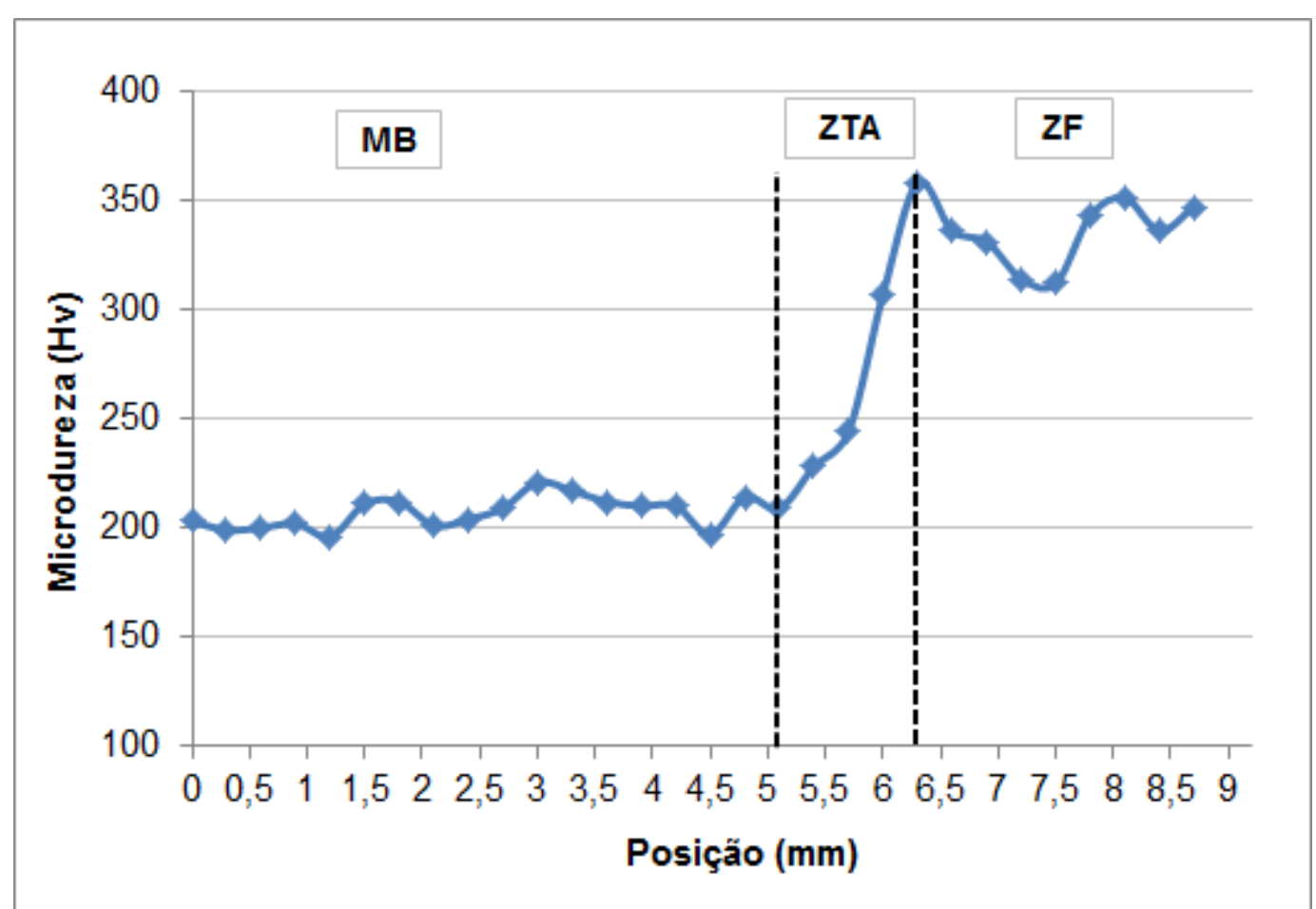

Figura 9. Perfil de microdureza em cordões de solda depositados por eletrodos AWS E7018 sobre aço API X65Q, corrente 70A. MB-Metal base; ZTA-Zona Termicamente Afetada; ZF-Zona Fundida.

Pode-se observar que, para o aumento de corrente de $70 \mathrm{~A}$ para $150 \mathrm{~A}$, além do aumento da largura da ZTA, ocorreu também uma diminuição da microdureza, na 
ordem de $11 \%$ nas médias da ZTA, e de $22 \%$ nas médias da zona fundida. De acordo com Eroglu et al. [15], isso ocorre porque o aumento da energia de soldagem leva a uma ZTA maior, por outro lado, essa ZTA será formada por constituintes de menor dureza, uma vez que a taxa de resfriamento foi menor. A zona fundida na condição de maior aporte térmico apresentou menor quantidade de ferrita acicular, constituinte que, devido à sua morfologia refinada e elevada densidade de discordâncias, confere maior resistência mecânica ao material [16].

Tsay et al. [17] também realizaram soldagem no aço API $5 \mathrm{~L}$ X65 com eletrodos revestidos e reportaram os valores de microdureza Vickers mais elevados na região de grãos grosseiros da ZTA, semelhante ao obtido no presente trabalho.

\section{CONCLUSÕES}

O dispositivo de soldagem mecanizada por eletrodos revestidos desenvolvido no Laboratório de Soldagem do DEMET/UFOP apresenta condições adequadas de controle e repetibilidade dos parâmetros de soldagem para estudos de Metalurgia da Soldagem.

A deposição de cordões de solda a partir de eletrodos AWS E7018 com 3,25mm de diâmetro apresentou variação da velocidade de soldagem à medida que o eletrodo é consumido, porém, para eletrodos de menor diâmetro, a velocidade é praticamente constante em todo o cordão.

O aumento do aporte de calor de $0,67 \mathrm{~kJ} / \mathrm{mm}$ para $1,24 \mathrm{~kJ} / \mathrm{mm}$ na deposição de cordões de solda a partir de eletrodos AWS E7018 sobre um aço microligado API X65Q resultou em aumento do $\Delta \mathrm{t}_{800-500}$ de $4,1 \mathrm{~s}$ para $6,5 \mathrm{~s}$.

$\mathrm{O}$ aumento do $\Delta$ t800-500 nos cordões depositados sobre aço API X65Q reduziu em $21 \%$ a proporção de ferrita acicular no metal de solda, o que, por sua vez, reduziu a dureza da ZF em aproximadamente $22 \%$.

\section{Agradecimentos}

Os autores agradem à VSB pela doação do Material e à FAPEMIG pelo apoio financeiro para participação neste evento.

\section{REFERÊNCIAS}

1 Felizardo I. Estudo Experimental e Numérico do Aquecimento de Eletrodos Revestidos durante a Soldagem. Belo Horizonte. Tese [Doutorado em Engenharia Mecânica] Departamento de Engenharia Mecânica, Universidade Federal de Minas Gerais; 2003.

2 Marques PV, Modenesi PJ, Bracarense AQ. Soldagem: Fundamentos e Tecnologia. $3^{a}$ ed. Belo Horizonte: Editora da UFMG; 2011.

3 Rogers P, Hall K. Gravity welding and high recovery electrodes. Welding and Metal Fabrication. 1987; v. 55.

4 Davis J, Ferjutz K. ASM Handbook: Welding, Brazing and Soldering. Ohio: ASM International; 1993. v. 6.

5 Dantas CM. Desenvolvimento De Uma Garra Instrumentada Para Soldagem Robotizada Com Eletrodo Revestido. Belo Horizonte. Dissertação [Mestrado em Engenharia Mecânica] - Departamento de Engenharia Mecânica, Universidade Federal de Minas Gerais; 2006.

6 Monteiro LS. Estudo de Ciclos Térmicos em Juntas Soldadas de um Aço de Alta Resistência e Baixa Liga Através do Método "In Situ". São Paulo. Dissertação [Mestrado em Engenharia Mecânica] - Faculdade de Engenharia Mecânica, Unicamp; 2004. 
$7 \quad$ Kou S. Welding Metallurgy. $2^{\text {a }}$ ed. Hoboken: John Wiley \& Sons, Inc; 2002.

8 Colpaert $\mathrm{H}$. Metalografia dos Produtos Siderúrgicos Comuns. Revisão técnica André Luiz V. da Costa e Silva. 4aㅡ ed. São Paulo: Edgard Blucher; 2008.

9 American Society for Testing and Materials. ASTM E562: Standard Test Method for Determining Volume Fraction by Systematic Manual Point Count. West Conshohocken: ASTM; 2011.

10 American Society for Testing and Materials. ASTM A370: Standard Test Methods and Definitions for Mechanical Testing of Steel Products. West Conshohocken: ASTM; 2012.

11 Farias JP, Dutra JC. Efeito do Tipo de Fonte de Energia Sobre a Estabilidade do Arco de Eletrodos Revestidos. XII Congresso Brasileiro de Engenharia Mecânica - COBEM. 1993.

12 Cavalcanti CAN. Comparação entre o comportamento de eletrodos revestidos utilizando dispositivos de soldagem por gravidade e com controle automático do comprimento do arco elétrico. Porto Alegre. TCC [Graduação em Engenharia Mecânica] - Departamento de Engenharia Mecânica, Universidade Federal do Rio Grande do Sul; 2011.

13 Det Norske Veritas As. DNV-OS-F101: Offshore standard. Submarine pipeline systems. Hovik: DNV; 2013.

14 Araújo LCS. Influência de Tratamentos Térmicos Pós Soldagem na Microestrutura e Propriedades Mecânicas de juntas de aço que atende ao grau API $5 \mathrm{~L}$ X70Q Soldado pelo Processo SMAW. Ouro Preto. Dissertação [Mestrado em Engenharia de Materiais] - Rede Temática em Engenharia de Materiais, Universidade Federal de Ouro Preto; 2013.

15 Eroglu M, Aksoy M, Orhan N. Effect of coarse initial grain size on microstructure and mechanical properties of weld metal and HAZ of a low carbon steel. Materials Science and Engineering: A. 1999; 269: 59-66.

16 Albuquerque SF, Maciel TM, Santos MA, Bracarense AQ. Avaliação da Microestrutura e Propriedades Mecânicas de Metais de Solda Obtidos por Processos de Soldagem Manual e Automatizado utilizado na Soldagem de Aço API 5L X80. Soldag. Insp. 2011; 16: 322-332.

17 Tsay LW, Chen YC, Chan SLI. Sulfide stress corrosion cracking and fatigue crack growth of welded TMCP API 5L X65 pipe-line steel. International Journal of Fatigue. 2001; 23(2): 103-113. 